Industrial Relations, Vol. 52(4), 712-35 (October 2003).

\title{
THE DUAL TRANSFORMATION OF \\ WORKPLACE DISPUTE RESOLUTION
}

Alexander J.S. Colvin*

* Department of Labor Studies and Industrial Relations, Pennsylvania State University, University Park, PA. E-mail: ajc10@psu.edu. This paper is based on a multiyear research project on the Telecommunication Service Industry, funded by the Alfred P. Sloan Foundation. The author thanks Harry Katz, Wendy Boswell, Rosemary Batt, Jeffrey Keefe, and Katherine Stone for helpful comments. 
Abstract: This study examines the impact on grievance rates of variation in the structure of nonunion dispute resolution procedures and in systems of work organization. Nonunion dispute resolution procedures that feature non-managerial decision-makers had higher grievance rates than nonunion procedures with managerial decision-makers. Grievance rates were also lower in workplaces that had adopted self-managed teams.

\section{Introduction}

Over recent decades, American industrial relations has been transformed through two different, though related, processes. First, the institutional structures of industrial relations have been transformed by the declining coverage of union representation and the coincident rise of individual employment rights laws. This shift away from direct union representation and towards individualized employment relations has increased the importance for employment relations of the processes of governance of the nonunion workplace and raises the issue of a potential employee voice gap due to the lack of institutional structures for employee representation and dispute resolution in the nonunion workplace (Freeman and Rogers 1999). Second, traditional forms of work organization and related human resource practices have been transformed by the advent of new forms of work organization, following models such as high involvement work systems, lean production, and self-managed work teams.

In the heyday of the New Deal industrial relations system in the 1950's and 1960's, one of the strongest contrasts between union and nonunion workplaces was the almost universal adoption of formal grievance-arbitration procedures with high levels of conflict and usage in unionized workplaces versus the general absence of formal dispute resolution procedures in the nonunion workplace (Slichter, Healy, and Livernash 1960). In more recent years, the simple dichotomy of this picture is beginning to change with the growing adoption of formal dispute

resolution procedures in the nonunion workplace (Feuille and Delaney 1992). Historically, a major problem with dispute resolution procedures adopted in nonunion workplaces was that 
employees often did not trust the effectiveness of the procedures and the procedures commonly fell into disuse and neglect (Slichter, Healy, and Livernash 1960). Although evidence on the usage of current day procedures is limited to studies of only a few specific companies' procedures, this limited evidence suggests that although usage levels for nonunion procedures are substantially lower than for union procedures, such usage is not negligible (Lewin 1987, 1990, 1999). Furthermore, in contrast to the relative uniformity of union grievance-arbitration procedures, the structure of nonunion procedures varies widely (Ewing 1989; Feuille and Chachere 1995) and it may be that usage levels vary significantly with the type of nonunion procedure used and the degree to which it incorporates due process protections.

Use of dispute resolution procedures cannot be examined in isolation from the underlying conflicts and patterns of relations in the workplace. To the degree that change occurs in the overall relationship between employees and management in the workplace, we would expect this to be reflected in the usage of the procedures available for resolution of disputes. Changes that enhance employee involvement in decision-making in the workplace are particularly relevant here in that they have the potential to change both the level and nature of conflict between employees and management and how employees approach resolution of disputes.

This study investigates how this dual transformation of industrial relations is affecting the process of dispute resolution in the workplace. It examines the impact on dispute resolution activity in the workplace of variation in both the structure of nonunion dispute resolution procedures and the adoption of new forms of work organization. The data that will be analyzed was gathered in a 1998 survey of dispute resolution practices in 180 establishments in the telecommunications industry. 


\section{Dispute Resolution Procedures}

The establishment of grievance-arbitration procedures to resolve disputes in the unionized workplace is one of the singular achievements of the American industrial relations system. What has been dubbed the 'constitutional governance' of the workplace through the system of industrial jurisprudence administered by a cadre of neutral labor arbitrators constitutes one of the strongest differentiators of the unionized workplace from the nonunion workplace where dispute resolution procedures are often entirely absent. Yet many nonunion workplaces increasingly do have some type of formal procedure for resolving employee grievances or complaints (Feuille and Chachere 1995). Furthermore, some of these nonunion procedures now feature non-managerial decision-makers, such as peer review panels and nonunion arbitration procedures (Feuille and Delaney 1992; Feuille and Chachere 1995). With the decline in the coverage of union representation, for a large section of the workforce these nonunion procedures are the only type of dispute resolution procedure available in the workplace. Many of these procedures may lack the extensive due process protections available under union grievancearbitration procedures, however some nonunion procedures do include more substantial protections than others and we know little about how this affects the usage by employees of these procedures (Lewin 1999).

Dispute resolution procedures in the nonunion workplace are characterized by a high degree of variation in both incidence and structure, with many procedures suffering from due process deficiencies that may discourage employees from filing grievances (Feuille and Delaney 1992). Estimates suggest that only around one-half of all nonunion workplaces have some type of formal dispute resolution procedure covering employees (Feuille and Chachere 1995). 
Among those workplaces with nonunion dispute resolution procedures, one of the most common and important due process deficiencies is the lack of a non-managerial decision maker. Under many nonunion procedures, employee complaints are reviewed and decided by higher-level managers (Feuille and Chachere 1995). From an employee perspective, these managerial decision-makers are likely to be seen as relatively favorably disposed to the positions taken by their fellow managers (Klaas and Feldman 1993).

However in recent years, increasing numbers of organizations have begun to incorporate non-managerial decision makers into nonunion dispute resolution procedures. Two of the more common types of procedures employing non-managerial decision-makers are peer review procedures and nonunion arbitration procedures (Feuille and Delaney 1992). Under peer review procedures, employees who are peers of the complainant sit on panels that review grievances (McCabe 1997). Under nonunion arbitration procedures, a neutral third-party arbitrator hears and decides employee complaints. Adoption of nonunion arbitration procedures received a major impetus from the Supreme Court's 1991 decision in Gilmer v. Interstate Johnson/Lane, 500 U.S. 20 (1991), where it held that nonunion arbitration agreements had preclusive effect on litigation concerning statutory employment rights (Stone 1999). More recently, the Supreme Court rejected challenges to the applicability of the Federal Arbitration Act to employment contracts in Circuit City v. Adams, 532 U.S. 105 (2001) thereby reconfirming the ability of employers to require arbitration agreements as a mandatory part of nonunion employment contracts. While these procedures have been criticized as comparing unfavorably to the standards of due process found in the courts or under union grievance-arbitration procedures, the alternatives faced by most nonunion employees in the workplace may be less appealing. Both peer employees and arbitrators have at least the potential to be viewed by employees as more 
independent and neutral decision-makers than the managers who continue to have the final say under typical nonunion procedures (Lewin and Peterson 1990; Klaas and Feldman 1993).

Previous writing on nonunion grievance procedures offers two broad generalizations about their usage. First, it is suggested that grievance rates under nonunion procedures are lower than grievance rates under union procedures (Lewin and Peterson 1990; Feuille and Delaney 1992). Second, it is argued that a major reason for lack of usage of nonunion procedures is the absence of the due process protections commonly included in union procedures (Epstein 1975; Lewin and Peterson 1990). A corollary to this argument is the suggestion that among nonunion procedures, grievance rates should be higher where procedures include due process protections such as provision for a neutral decision maker as the final step in the procedure. Put alternatively, provision of neutral decision makers should increase both the probability of employee success in grievances and perceptions of procedural fairness. Greater chances of success and the perception that a dispute resolution procedure is procedurally fair should in turn lead to a higher likelihood of employees using the procedure to resolve disputes in the workplace, what I will refer to as the neutrality effect, thereby increasing grievance rates under these procedures.

Hypothesis 1: Rates of usage of nonunion grievance procedures will be higher where the procedures include non-managerial decision makers.

A general question arising when examining differences in grievance rates is how they relate to differences in the nature of conflict in the workplace. When we are comparing grievance rates between workplaces with relatively similar grievance procedures, such as in comparing rates among a set of unionized workplaces, differences in grievance rates may be interpretable as reflecting differences in levels of conflict in the workplaces. However, if we 
compare workplaces with very different types of grievance procedures, differences in grievance rates may not reflect a difference in underlying levels of conflict in the workplace, but rather differences in the degree to which that conflict is given formal expression through the grievance procedures. That unionized workplaces feature relatively high grievance rates compared to nonunion workplaces does not necessarily reflect an absence of conflict in the nonunion workplace, but rather may reflect the channeling of conflict into the more formal structure of grievance-arbitration procedures in unionized workplaces. Put alternatively, one way of viewing the increased use by employees of grievance procedures to attempt to resolve conflicts is as a formalization of dispute resolution in the workplace. However to observe that increased grievance rates resulting from adoption of procedures with stronger due process protections represents a formalization of dispute resolution is not to diminish its significance. Indeed to the degree that there is a neutrality effect in which the adoption of procedures with more independent decision-makers in nonunion workplaces leads to a greater formalization of dispute resolution, this represents a noteworthy shift in the institutional process through which conflict is resolved in the nonunion workplace.

\section{High Involvement Work Systems}

In research investigating the transformation of industrial relations at the workplace level, high grievance rates were seen as one of the key characteristics of traditional adversarial patterns of relations in the workplace (Kochan, Katz, and McKersie 1986). Conversely, lower grievance rates and faster, more informal resolution of disputes were identified as part of transformed systems or patterns of industrial relations that were associated with improved organizational performance (Ichniowski 1986; Katz, Kochan, and Weber 1985; and Cutcher-Gershenfeld 1991). 
If lower grievance rates are part of such transformed patterns of industrial relations, then we would expect grievance rates to vary in conjunction with other practices and behaviors that form part of these workplace industrial relations systems (Katz, Kochan, and Weber 1985; Kochan, Katz, and McKersie 1986). In a study of industrial relations systems in steel mini-mills, Arthur (1992) identified a similar pattern of practices, which he described as a 'commitment maximizing system', including enhanced employee participation, decentralized decision-making, and high levels of general training of employees. A due process variable consisting of the percentage of complaints handled through formal procedures was included in the cluster analysis in Arthur's (1992) study, but failed to load significantly on the high commitment clusters, perhaps due to a single variable failing to adequately capture the effect of simultaneous variation in both dispute resolution procedure structure and usage.

There are three different ways in which high involvement work systems may lead to lower rates of usage of dispute resolution procedures. First, greater trust and cooperation between employees and management under high involvement work systems may lead to a reduction in the overall level of conflict in the workplace (Kochan, Katz, and McKersie 1986). This conflict reduction effect should reduce the number of underlying disputes in the workplace and thereby also reduce the overall rate of usage of dispute resolution procedures. Second, there may be an impact of high involvement work systems on how disputes are resolved in the workplace. Take the example of self-managed teams in the workplace, one of the practices most strongly associated with high involvement work systems. Under self-managed teams, workers are granted broader decision-making authority in the workplace, in contrast to off-line participation programs that are more narrowly focused on production and quality issues (Appelbaum and Batt 1994). To the degree that workers are able to resolve more problems and 
disputes informally through these other structures for participation in the workplace, we would expect usage of dispute resolution procedures to be reduced (Cutcher-Gershenfeld 1991). This informal resolution effect would predict a reduction in rates of usage of dispute resolution procedures even if the level of underlying conflict were not affected. Finally, the involvement of employees in decision-making in team based production systems and greater labor-management trust inherent in these systems may also produce an effect in which decisions such as application of disciplinary rules are seen as having greater legitimacy to employees. This legitimization effect would also lead to a prediction of a reduction in grievance rates under high performance work systems apart from any effect on the underlying level of conflict in the workplace. Based on the combination of these effects, the prediction is that we should find high involvement work systems, and more particularly self-managed work teams, associated with lower levels of usage of grievance procedures, holding the type of procedure constant.

Hypothesis 2: Holding the type of grievance procedure constant, grievance rates will be lower where self-managed work teams have been introduced in the workplace.

\section{The Data}

Sample and Survey Methods

The data for this study was collected through a 1998 telephone administered survey of establishments in the telecommunications industry. Focusing the study on data from a single industry has the advantage that it reduces the effect of extraneous variation, such as that arising from differences between industries in workplace environments, technology, or labor markets. Use of the establishment as the unit of analysis in this study follows prior research on both grievance rates (Cappelli and Chauvin 1991; Kleiner, Nickelsburg, and Pilarski 1995) and work 
organization and employment practices (Osterman 1994, 2000). Typical establishments, i.e. individual workplaces, in this industry would be either customer service centers or garages from which technicians are dispatched in installation and repair trucks. Although the industry has a number of large firms, most of these individual establishments are relatively small in size, with fewer than a hundred employees in each workplace.

The sampling frame was constructed by drawing a stratified random sample from a population of establishments in the telecommunications industry provided by the Dun and Bradstreet listing of establishments, which includes SIC code industry classifications. Establishments were stratified by size, with almost all establishments with more than 100 employees included in the sample. Smaller establishments were stratified by SIC code so that the total sample reflects the relative proportion of establishments in the three major parts of the industry: wireline (SIC 4813); cellular (SIC 4812); and cable TV (SIC 4841). Because internet providers are an important new part of the industry that is not systematically captured by SIC code, additional ISPs were identified through the Directory of National Dial-up Providers and Area Codes of Operation.

A university-based survey team administered the survey by telephone in the Summer and Fall of 1998. The data was collected in two stages. Respondents first answered a survey collecting data on work organization and employment practices. A few weeks later a random subset of the establishments answered a second survey asking detailed questions on grievance procedures and activity. The response rate for the initial survey was 54 percent and for the follow-up survey the response rate was 75 percent, producing a combined effective response rate of 40.5 percent, which yielded a total of 302 respondents. Individual informants were in most cases the general managers for the establishments and were the same for both the first and 
second surveys. Comparisons of means between respondents for the first and second surveys revealed two statistically significant differences. Compared to the total sample of respondents to the first survey, the sample of respondents for the second survey were located in areas with lower unemployment rates ( 4.1 percent versus 4.8 percent, $\mathrm{p}<.01$ ) and had slightly lower average employee education levels (13.6 years versus 13.9 years, $\mathrm{p}<.10)$. There were no other statistically significant differences between the respondents to the two surveys on the independent variables. Based on these comparisons, differences in the sample due to dropouts between the two survey rounds exist, but appear relatively minor. An area where differences in respondents between the two survey rounds were likely, but could not be tested, was in the structure and usage of dispute resolution procedures, which were only asked about in the second survey. Respondents were informed of the general subject of the survey in obtaining consent to administer the survey, which may have affected their likelihood of responding.

Analysis focused on those establishments with either union or nonunion dispute resolution procedures. Additional elimination of establishments with missing data on the variables of interest produced a final sample of 180 establishments used in the data analysis. Elimination of respondents who were unable to provide information on levels of usage of procedures has an additional effect in biasing the sample towards establishments where procedures are sufficiently formalized that respondents would be able to provide this type of information. As a result, the sample analyzed here is one that includes among the nonunion establishments a relatively high proportion of establishments with more formalized procedures. It therefore provides a more conservative estimate of the degree of variation in dispute resolution among nonunion establishments by understating the contrast between the more formalized 
procedures captured in this analysis and the nonunion workplaces with only informal processes for conflict resolution.

\section{Dependent Variables}

A major methodological challenge in research on grievance procedures lies in the difficulty of gathering accurate data on grievance activity. This is one of the reasons for use of the establishment level of analysis in this study. In prior case study research, I found that managers at the corporate or divisional levels within the firms studied were generally unable to provide information on levels of grievance activity for the whole firm or division (Colvin 1999). By contrast, at the establishment level managers were better able to provide estimates of grievance activity levels for their own workplace. Clearly there is still likely to be a degree of measurement error in such estimates, however an additional factor reducing the size of the error in the estimates is the relatively small size of establishments examined in this study. The typical (median) establishment in this study had only 65 employees and only a single layer of management between the general manager of the establishment and front-line supervisors. That noted, it is important to recognize that there is a trade-off in collecting this type of survey data between the ability to obtain data on broad differences across a larger number of establishments and lower precision of measurement. The estimates reported here should be viewed with this caution in mind.

Two additional major challenges confront efforts to measure grievance activity in a way that permits comparison between organizations. The first challenge is variation in the extent of coverage of different types of disputes. This is less of a problem with comparisons among union procedures given the common feature of union grievance-arbitration procedures in covering any 
dispute under the collective bargaining agreement. In contrast, variation in coverage of nonunion procedures is much greater with some procedures allowing any work related grievance, whereas other procedures are more restrictive, for example only allowing grievances over discipline and discharge decisions (Feuille and Chachere 1995). As a result, comparisons of overall grievance rates between nonunion procedures are likely to be influenced by the extent of coverage of disputes as well as by the structure of the procedure and other due process features. In order to achieve comparability of measures, the analysis here is restricted to a single category of grievances, those concerning discipline, and only includes procedures that cover this category of disputes. Disciplinary grievances provide a useful category to examine because they are one of the most common types of grievances in the workplace (Lewin and Peterson 1988; Lewin 1999). In addition, among nonunion procedures that restrict the types of grievances that may be brought by employees, discipline is one of the most common categories of grievances that are covered.

A second major challenge in comparing grievance rates between organizations with different grievance procedures is variation in levels of conflict in the workplace. Grievance rates are likely to increase with the level of conflict in the workplace. Put alternatively, the usage of grievance procedures will depend on both the number of grievable events occurring in the workplace and the willingness of employees to use the grievance procedure to resolve these potential disputes (Bemmels and Foley 1996). Specifically, the rate of grievances that are appeals of disciplinary decisions will depend on both the number of employees who are disciplined and the willingness of employees to use the grievance procedure to challenge disciplinary decisions. To attempt to capture both absolute and relative levels of grievance activity, two different dependent variables are examined in this study. The first dependent 
variable is the Grievance Rate, measured as the natural log of the estimated average annual number of grievances concerning disciplinary decisions filed per hundred employees covered by the procedure. Measuring the disciplinary grievance rate as the total annual number of grievances per hundred employees follows a number of past studies that have used similar measures of total levels of grievance activity (e.g. Lewin and Peterson 1988; Lewin 1990; Cappelli and Chauvin 1991). The second dependent variable is the Appeal Proportion, measured as the estimated average annual number of disciplinary grievances divided by the annual number of employees subject to discipline. To exclude more informal disciplinary warnings, respondents were asked about disciplinary decisions where written warnings, suspensions, demotions, terminations or other similar penalties were imposed. However, it should also be recognized that the circumstances leading to the imposition of discipline depend on the work rules of the individual establishment, which introduces an additional source of variation. This second dependent variable provides the benefit that it is measured relative to the number of grievable events. Put alternatively, the Appeal Proportion is a dependent variable that itself contains a control for the level of conflict in the workplace that may produce grievances. A limitation in these measures is that respondents were not asked to provide an average grievance rate for a multi-year period (e.g. a 3 or 5 year average grievance rate) based on archival sources, which would have been preferable, though more difficult for the respondents to provide. As a result, additional measurement error may have been introduced from rates being estimated based on a single year, particularly where an establishment experienced an anomalously high or low grievance rate for that year. 


\section{Independent Variables}

Dispute Resolution Procedures. To enhance consistency and comparability, the survey asked about the structure of dispute resolution procedures covering core employees in the establishment, i.e. those employees performing the core work in the establishment. For example, if the establishment were a calling center, the core employees would be the customer service workers who respond to customers on the telephones, or if the establishment were a garage that dispatches repair trucks, the core employees would be the field technicians dispatched with the trucks who do the repair and service work in the field. A single dichotomous variable, Union, measures coverage by a union grievance-arbitration procedure $(1=$ yes, $0=$ no $)$. The definition of core employees was sufficiently narrow that bargaining units in this industry would cover all core employees, rendering the core employees in the establishment either entirely union or entirely nonunion. For nonunion workplaces, two dichotomous variables measure whether the dispute resolution procedure includes Nonunion Arbitration $(1=$ yes, $0=$ no) or Peer Review ( 1 $=$ yes, $0=$ no). The residual category thus consists of nonunion establishments where the dispute resolution procedure includes neither nonunion arbitration nor peer review elements.

Teams. The presence of team forms of work organization is captured by a single dichotomous variable, Self-Managed Teams, indicating whether or not core employees are organized into self-managed teams $(1=\mathrm{yes}, 0=\mathrm{no})$. Given that in some workplaces only a very small proportion of workers may actually be organized into teams, a minimum criterion was used whereby only workplaces where at least 20 percent of the workers participated in teams were counted as having teams present. Although this is a relatively simple measure compared to some more complex indices that have been used to represent high involvement work systems in other studies, it has the advantage of more direct and straightforward interpretation. 


\section{Control Variables}

Other Employment Practices. Although the focus in this study is on the effect of selfmanaged teams, it needs to be recognized that other employment practices are likely to affect grievance rates and to attempt to control for their effects in the analysis. Two employment practices that are important within the telecommunications industry and may affect grievance rates are electronic monitoring and employee mobility. In the telecommunications industry, electronic monitoring is commonly used as a method of monitoring employees and increasing the pace of work. To the degree that it increases the pressures placed on employees in the workplace and leads to higher levels of stress, electronic monitoring may be associated with other manifestations of conflict in the workplace, such as increased grievance rates. Electronic Monitoring, is measured as the proportion of work performed that is electronically monitored, so that if half the employees were electronically monitored during half of their working time, the proportion of work performed that is electronically monitored would be one quarter. Another employment practice that may influence grievance rates is the mobility of employees to other positions and jobs within the establishment. Where employees are subject to what they perceive as unfair discipline from a supervisor, one alternative to filing a grievance through a dispute resolution procedure is to seek to be transferred to another position in the establishment where the employee will no longer be working under the same supervisor. Thus, employee mobility within the establishment may be associated with lower grievance rates. Employee mobility is measured as the proportion of employees who have moved to their current job from another position within the same company. 
External Labor Market. An implication of exit-voice trade-offs in the usage of grievance procedures is that grievance rates are likely to vary with the attractiveness of alternative job opportunities in the external labor market. Cappelli and Chauvin (1991) found in a study of the use of union grievance procedures that grievance rates increased with local unemployment rates. In addition, they found that grievance rates were higher the greater the wage premiums received by employees relative to similarly situated workers in their local labor markets (Cappelli and Chauvin 1991). These findings support the need to control for variation in local labor market conditions in any inter-organizational comparison of grievance rates. The impact of the external labor market on grievances is captured by two variables. The Local Unemployment Rate represents the availability of alternative employment opportunities and is expected to be positively related to the grievance rate. Similarly, the higher the level of pay relative to local cost of living, the more valuable will be the existing employment compared to alternative opportunities and hence the higher the grievance rate. The variable Average Pay is the average pay of core workers in the establishment, converted to a relative measure where $1.00=\$ 40,000$ and adjusted for local cost of living levels.

Workforce Characteristics. Four variables provide controls for workforce characteristics likely to affect grievance rates. The variable Education Level is measured as the average number of years of education for workers in the establishment. Education level is likely to influence employment prospects in the external labor market and hence the relative attractiveness of using grievance procedures as a voice mechanism to resolve problems instead of the exit alternative of seeking alternative employment. Length of tenure is likely to affect grievance rates if shorter tenure workers have relatively little investment in their existing job and a greater likelihood of seeking to resolve disputes by finding alternative employment rather than using dispute 
resolution procedures. The variable Low Tenure is measured as the proportion of the workforce with less than one year of employment tenure with the establishment. Two dummy variables are included as controls capturing the three major occupational groups in the industry, Customer Service and Office Technicians, with field technicians, the third major occupational group, being the omitted category. In each establishment, the core employees would be members of one of these three occupational groups, e.g. customer service workers in a calling center or field technicians in a garage that dispatches repair trucks, so that these variables also control for differences in the type of establishment.

\section{Estimation Method}

A problem arises in estimation due to the limited nature of the dependent variables. The distribution of the first dependent variable, the Grievance Rate, is bounded below at zero due to the impossibility of negative grievance rates and there are a number of observations in the sample at the left limit of zero. To account for the effect of this censoring of the dependent variable for values below zero, the equation for this variable is estimated using a tobit model (Long 1997). Use of a tobit model introduces the complication in interpretation of effect sizes that coefficient estimates for the model represent changes in the latent variable $\mathrm{y}^{*}$, rather than the censored variable y. For interpretation of effect sizes, the tobit coefficients need to be multiplied by the appropriate conversion factors to produce the change in the observed censored variable y (Long 1997). ${ }^{1}$ All effect sizes reported here for the tobit coefficients are calculated for

\footnotetext{
${ }^{1}$ For a tobit model with a lower limit, the formula for the total change in the observed variable y is $F(z) B$, where $B$ is the unadjusted tobit coefficient and $\mathrm{F}(\mathrm{z})$ is the cumulative density function for the probability of the observation being uncensored (Long 1997: 209). The corresponding formula for a tobit model with both upper and lower limits is $\left[F\left(z_{U}\right)-F\left(z_{L}\right)\right] \beta$, where $F\left(z_{U}\right)$ and $F\left(z_{L}\right)$ represent the cumulative density functions associated with the upper and lower limits respectively, so that the term $\left[\mathrm{F}\left(\mathrm{z}_{\mathrm{U}}\right)-\mathrm{F}\left(\mathrm{z}_{\mathrm{L}}\right)\right]$ represents the probability of an uncensored observation (Long 1997: 213).
} 
changes in the observed grievance rate based on this conversion. The grievance rate is analyzed in logged form in the estimation equations due to the strongly right-skewed form of the distributions for this variable. Expression of the grievance rate in logged form allows the additional advantage of permitting interpretation of effect sizes as percentage changes in the dependent variable, once the appropriate conversion is made using the anti-log. The second dependent variable, the Appeal Proportion is expressed as a proportion of total disciplinary decisions. Given that this dependent variable is a proportion bounded by the values 0 and 1 , it has both an upper and lower limit. The prediction equation for the Appeal Proportion was therefore also estimated using a tobit model, but specified with both an upper and a lower limit. In all estimations a correction to the standard errors was included to account for establishments that were part of the same parent company, which introduces a potential for lack of independence of observations. Ownership was, however, relatively dispersed in the sample, with 103 different parent companies among the 180 establishments.

\section{Results}

Overall means and standard deviations for all variables are reported in Table 1, as well as the means calculated separately for nonunion and union establishments. The correlation matrix is reported in Table 2.

Tables $3 \mathrm{a}$ and $3 \mathrm{~b}$ provide a simplified overview of the structure of the data. In Table $3 \mathrm{a}$ the means for each of the dependent variables are reported separately for nonunion and unionized establishments and for establishments with and without teams. As expected, average annual disciplinary grievance rates are higher in unionized establishments (5.3 per 100 employees) than in nonunion establishments (2.0 per 100 employees). Similarly, the proportion of disciplinary 
decisions appealed is higher in unionized establishments (0.55) than in nonunion establishments (0.18). These differences are unsurprising and reflect both differences in the structure of grievance procedures and the many other differences between unionized and nonunion workplaces. Not least among these is the institutionalized status of the union as an actor in the workplace and resulting strategic uses made by the union of the grievance procedure to exert pressure on management. Although there are some differences when the results are broken down by the presence or absence of teams in the workplace, no consistent pattern emerges in this preliminary comparison. Among nonunion establishments, grievances rates are somewhat lower where teams are present (1.7 grievances per 100 employees versus 2.1$)$, whereas discipline appeal proportions are slightly higher where teams are present (.20 versus .17). Conversely among unionized establishments, grievance rates are higher where teams are present (6.1 versus 5.1), but discipline appeal proportions are lower (.46 versus .57).

To examine more closely the effect of variation in the structure of nonunion procedures, Table $3 \mathrm{~b}$ reports means for nonunion establishments categorized by the type of procedure. The most striking result is that usage of procedures, measured either by disciplinary grievance rates or appeal proportions, is substantially higher where either peer review or nonunion arbitration is present compared to other types of nonunion procedures. Whereas the mean annual disciplinary grievance rate is 2.9 per 100 employees for peer review procedures and 3.2 for nonunion arbitration, the mean rate is only 1.3 for other nonunion procedures. Similarly, whereas the mean appeal proportion is .30 for procedures with peer review and .34 for procedures with nonunion arbitration, it is only .11 for other nonunion procedures. This simple comparison supports the basic suggestion that inclusion of non-managerial decision-makers in nonunion dispute resolution procedures increases the level of usage by employees. Table $3 \mathrm{~b}$ further 
separates out the mean grievance rates, and appeal proportions for each type of procedure by the presence or absence of self-managed teams in the workplace. For the disciplinary grievance rate there is a relatively simple pattern in which for each type of procedure, the grievance rate is lower in workplaces with self-managed teams than in workplaces without such teams. Appeal proportions are similarly lower for procedures with nonunion arbitration and other types of nonunion procedures where teams are present, but in contrast appeal proportions are higher where teams are present for workplaces with peer review procedures.

Table 4 reports the results of estimation of prediction models for the dependent variables with controls included. As noted earlier, the prediction equations were estimated using tobit models. Separate models are estimated for nonunion and unionized establishments. Although differences between union and nonunion procedures are of interest, the wide range of differences in the area of dispute resolution between union and nonunion workplaces makes direct statistical tests comparing these procedures problematic for this type of data. In addition to differences in the structure of procedures, differences in grievance rates between unionized and nonunion establishments are likely to be influenced by factors such as the role of grievances as a mechanism for unions to put pressure on management in the workplace, the role of union shop stewards in handling grievances, and the role of the jointly negotiated collective agreement as the substantive basis for grievances. In general, the stronger institutional structures in unionized workplaces are likely to produce a much greater formalization of conflict resolution in the unionized compared to the nonunion workplace. As a result, the analysis will begin with models 1 and 2, examining the disciplinary grievance rate and appeal proportion for nonunion establishments, and then turn to models 3 and 4, examining the disciplinary grievance rate and appeal proportion for unionized establishments. 
For nonunion establishments, the first issue was the relationship between the structure of dispute resolution procedures and levels of usage of the procedures. The results support the predicted relationship between incorporation of non-managerial decision-makers into dispute resolution procedures and higher levels of usage by employees. Nonunion establishments with either peer review or nonunion arbitration procedures had significantly higher grievance rates and appeal proportions than basic nonunion procedures that used managers as decision makers. In model 1, compared to basic nonunion procedures, peer review procedures had grievance rates that were on average 43.1 percent higher $(\mathrm{p}<.05)$ and nonunion arbitration procedures had grievance rates that were on average 68.0 percent higher $(\mathrm{p}<.01)$. In model 2 , compared to basic nonunion procedures, peer review procedures had appeal proportions that were on average 13.4 percentage points higher $(\mathrm{p}<.05)$ and nonunion arbitration procedures had appeal proportions that were on average 18.5 percentage points higher $(\mathrm{p}<.01)$. These results provide support for the existence of the neutrality effect proposed in hypothesis 1 , whereby inclusion of non-managerial decision-makers in nonunion dispute resolution procedures increases the willingness of employees to use these procedures to resolve disputes.

To what degree do the higher levels of usage of procedures with non-managerial decision-makers reflect greater employee chances of success in challenging disciplinary decisions using these procedures? A major problem in answering this question is that employees are intelligent actors who are likely to include calculations of their probability of success or failure in deciding whether or not to file a grievance under a procedure. If employees believe that a procedure provides stronger due process protections and a better chance of getting a fair hearing for their complaint, they may be more likely to file a grievance even if they are unsure of the strength of their claim. By contrast, if the procedure only contains weak due process 
protections, employees may not consider it worthwhile to bring anything but a very strong case through the grievance procedure, particularly if they fear retaliation by supervisors for having filed a grievance. The result is that a weak procedure might have relatively low usage levels so that few management decisions are successfully challenged under the procedure, but still have a reasonably high employee win rate for the few grievances that are actually filed.

Table 5 presents results for two different measures of the probability of employee success for the procedures being examined here. Looking simply at employee success in appeals, defined as the proportion of appeals that result in full or partial reversing of the disciplinary decision, win rates were relatively similar across different types of procedures. Indeed, the mean employee win rate in appeals is actually somewhat lower for peer review (30.0\%) and nonunion arbitration $(36.4 \%)$ procedures than for other types of nonunion procedure (46.4\%). However, this comparison does not take into account the degree to which employees decide not to use procedures because they perceive little likelihood of success or fear retaliation. A better measure of overall employee success in using grievance procedures to challenge disciplinary decisions is obtained if we look at the proportion of all disciplinary decisions in the workplace that were fully or partially reversed through a successful appeal using the grievance procedure. Using this measure, the mean percentage of disciplinary decisions that are successfully appealed is much higher under peer review (9.9\%) or nonunion arbitration $(11.1 \%)$ procedures than under other types of nonunion procedure $(2.7 \%)$. These comparisons of success rates need to be viewed with caution given the inability to fully capture the selection effect arising from employee decisions concerning whether or not to file a grievance in a particular case and the resulting lack of standardization in the cases involved. However, what these results do indicate is that overall employees were able to successfully challenge disciplinary decisions more frequently under peer 
review or nonunion arbitration procedures than under other types of nonunion procedures, which provides some additional support for hypothesis 1.

The second issue examined was the relationship between work and employment systems and levels of usage of dispute resolution procedures. The results provide some support for this relationship among nonunion establishments, indicating an association between organization of the workforce into self-managed teams and lower usage of dispute resolution procedures. In model 1, establishments with self-managed teams had grievance rates that were on average 31.2 percent lower than for establishments without teams $(\mathrm{p}<.05)$. Similarly, based on model 2 , establishments with self-managed teams had on average a 9.6 percentage point lower appeal proportion than establishments without teams $(\mathrm{p}<.05)$. In the results for unionized establishments, reported in models 3 and 4, analysis is limited to the effects of variation in work and employment systems given the relative uniformity of union grievance-arbitration procedures compared to their nonunion counterparts. The results support a link between work and employment systems and grievance activity in the unionized workplace, but this relationship involves some different factors than in the nonunion establishments. In model 4, the proportion of disciplinary decisions appealed is reduced in unionized establishments where teams are present, by 20.4 percentage points compared to establishments without teams $(\mathrm{p}<.01)$. However, a similar result was not found for the disciplinary grievance rate in model 3, where the relationship for teams was not statistically significant. The finding of associations of selfmanaged teams with lower grievance rates in nonunion establishments and lower appeal proportions in both nonunion and unionized establishments supports the prediction from hypothesis 2 that use of self-managed teams would be associated with lower levels of usage of dispute resolution procedures to resolve disputes. 
Significant relationships are present for the two other work and employment systems variables of interest. Among unionized establishments, use of electronic monitoring of workers was associated with both higher grievance rates and higher appeal proportions. In model 3, grievance rates were on average 10.7 percent higher $(\mathrm{p}<.01)$ for each additional 10 percentage points of working time that was electronically monitored. In model 4, the appeal proportion was on average 3.7 percentage points higher $(\mathrm{p}<.01)$ in establishments for each additional 10 percentage points of working time that was electronically monitored. This provides strong support for the suggestion that electronic monitoring leads to greater levels of conflict and mistrust in the workplace. Finally greater internal job mobility was associated with higher appeal proportions for both nonunion $(\mathrm{p}<.10)$ and unionized $(\mathrm{p}<.05)$ establishments. For unionized establishments, an increase of 10 percentage points in the proportion of the workforce that had been transferred or promoted to their current position from within the organization was associated with a 2.6 percentage point higher appeal proportion for unionized establishments and 1.2 percentage points higher for nonunion establishments. This positive relationship between internal job mobility and the appeal proportion for both nonunion and union establishments is surprising to the extent that exit-voice theory would lead to the expectation that greater exit opportunities, in the form of internal job mobility, should lead to lower reliance on the voice mechanism of using dispute resolution procedures to resolve problems such as unfair imposition of discipline.

In interpreting these results, the limitations of the data should be kept in mind. As noted earlier, precise measurements of grievance activity are difficult to obtain and the measures obtained here likely contain a substantial amount of noise. Thus, the results should be viewed more as best estimates rather than precise measurements of the effects involved. What is noteworthy given the amount of noise likely involved is that substantial and statistically 
significant differences were nevertheless present in grievance rates among different types of nonunion dispute resolution procedures and between workplaces with and without self-managed teams.

\section{Conclusions}

With the declining coverage of union representation, dispute resolution procedures in the nonunion workplace are increasingly central to the issue of the provision of industrial justice in employment relations. Yet we know relatively little about how these nonunion dispute resolution procedures function and to what degree employees actually use these procedures. One of the most basic criteria for the effectiveness of a workplace dispute resolution procedure is whether or not employees are willing to use it to resolve problems. If employees do not indicate some degree of acceptance of a procedure through their own behavior by filing grievances, then whatever objectives the procedure is supposed to achieve are unlikely to be realized.

A key finding of this study is that use of non-managerial decision makers in nonunion grievance procedures is associated with increased usage of the procedures by employees. Two types of nonunion procedures incorporating non-managerial decision-makers, nonunion arbitration procedures and peer review procedures, where employees who are peers of the complainant hear and decide the grievance, had higher overall grievance rates and greater proportions of disciplinary decisions appealed compared to other nonunion procedures. In addition, a higher proportion of disciplinary decisions were fully or partially reversed through appeals under peer review and nonunion arbitration procedures than under other nonunion procedures. The findings of strong effects for the use of peer review procedures is surprising in 
that this type of procedure has received very little attention in the research literature. Given this effect and their interesting incorporation of the idea of employee involvement into the process of dispute resolution in the workplace, peer review procedures are clearly worthy of greater study in the future. Although nonunion arbitration has received relatively more academic and policy attention, the findings here are surprising given the criticisms that have been directed at the expansion of nonunion arbitration. One factor worth noting is that the criticisms that have been directed at nonunion arbitration procedures have primarily compared due process protections in nonunion arbitration to those provided by the court system. It is plausible that nonunion arbitration could represent a diminution of due process compared to the court system for disputes that result in litigation, but at the same time appear to employees as an enhancement of dispute resolution procedures at the workplace level. Indeed, in preliminary interviews for this study, many managers expressed the concern that although nonunion arbitration procedures might reduce the risks and costs of litigation, adoption of these procedures could lead to an increase in the number of employee grievances due to a perception that the employer was providing a new, improved set of procedures for hearing complaints.

At the same time as the institutional structure of governance of the American workplace has been transformed by declining union representation and the rising importance of nonunion dispute resolution procedures, the organization of the workplace has been in the process of transformation through the adoption of new forms of work organization. Viewed positively, employee involvement programs can be seen as reducing conflict in the workplace and enhancing employees' ability to articulate their interests and concerns in the workplace. Viewed negatively, employee involvement programs have been criticized as simply a new way of harnessing employees to management's interests and as undermining traditional institutional 
structures of interest representation. The results from this study indicate that employee involvement in the relatively strong form of self-managed teams is associated with lower usage of dispute resolution procedures. This reduction in usage of procedures was found for the proportion of disciplinary decisions appealed, not just for the overall grievance rate, suggesting that what is being observed is not simply an effect of reduced conflict levels in the workplace, but rather an effect on how disputes are being resolved. On a more negative note, the findings suggest that movement of work and employment systems in the opposing direction of greater control through use of electronic monitoring is producing increased conflict in the workplace, at least as reflected in higher levels of grievance activity.

Looking more broadly, what do developments in the area of workplace dispute resolution tell us about contemporary industrial relations? There is clearly no longer a simple dichotomy between unionized workplaces featuring grievance-arbitration procedures characterized by entrenched conflict and high grievance rates and nonunion workplaces with either no procedures or ineffective procedures that are rarely used by employees. Development of new types of nonunion dispute resolution procedures, particularly those featuring non-managerial decisionmakers, is resulting in some nonunion workplaces that have procedures that are used relatively frequently by employees, whereas others have much lower usage levels, and of course many nonunion workplaces continue to have no formal procedures at all. At the same time, differences in systems of work organization are creating additional variation in workplace dispute resolution. Thus the broader result of these dual shifts in institutional structures and systems of work organization is that we are seeing an increasing range of variation between different workplaces in employee access to procedures for the resolution of disputes. 


\section{References}

Appelbaum, Eileen, and Rosemary Batt. 1994. The New American Workplace:

Transforming Work Systems in the United States. Ithaca, NY: Cornell ILR Press.

Arthur, Jeffrey B. 1992. "The link between business strategy and industrial relations systems in American steel minimills." Industrial and Labor Relations Review, 45(3): 488506.

Bemmels, Brian, and Janice R. Foley. 1996. "Grievance Procedure Research: A Review and Theoretical Recommendations." Journal of Management, 22(3): 359-384.

Cappelli, Peter, and Keith Chauvin. 1991. "A Test of an Efficiency Model of Grievance Activity." Industrial and Labor Relations Review, 45(1): 3-14.

Colvin, Alexander J.S. 1999. "Citizens and Citadels: Dispute Resolution and the Governance of Employment Relations.” Ph.D. Dissertation, Cornell University, Ithaca, NY.

Cutcher-Gershenfeld, Joel. 1991. "The Impact on Economic Performance of a Transformation in Workplace Relations." Industrial and Labor Relations Review, 44(2): 241-260.

Epstein, Richard L. 1975. "The Grievance Procedure in the Non-union Setting: Caveat Employer.” Employee Relations Law Journal, 1(1): 120-127.

Ewing, David W. 1989. Justice on the Job: Resolving Grievances In the Nonunion Workplace. Boston, MA: Harvard Business School Press.

Feuille, Peter, and Denise R. Chachere. 1995. "Looking Fair or Being Fair: Remedial Voice Procedures in Nonunion Workplaces." Journal of Management, 21: 27-42.

Feuille, Peter, and John T. Delaney. 1992. "The Individual Pursuit of Organizational Justice: Grievance Procedures in Nonunion Workplaces." Research in Personnel and Human Resources Management, 10: 187-232.

Freeman, Richard B., and Joel Rogers. 1999. What Do Workers Want? Ithaca, NY: ILR Press.

Ichniowski, Casey. 1986. "The Effects of Grievance Activity on Productivity." Industrial and Labor Relations Review, 40(1): 75-89.

Katz, Harry C., Thomas A. Kochan, and Mark R. Weber. 1985. "Assessing the Effects of Industrial Relations Systems and Efforts to Improve the Quality of Working Life on Organizational Effectiveness.” Academy of Management Journal, 28(3): 509-526.

Klaas, Brian S., and Daniel C. Feldman. 1993. "The Evaluation of Disciplinary Appeals 
in Non-Union Organizations.” Human Resource Management Review, 3(1): 49-81.

Kleiner, Morris M., Gerald Nickelsburg, and Adam Pilarski. 1995. "Monitoring, Grievances, and Plant Performance." Industrial Relations, 34(2): 169-189.

Kochan, Thomas A., Harry C. Katz, and Robert B. McKersie. 1986. The Transformation of American Industrial Relations. New York: Basic Books.

Lewin, David. 1987. "Dispute Resolution in the Nonunion Firm: A Theoretical and Empirical Analysis." Journal of Conflict Resolution, 31(3): 465-502.

Lewin, David. 1990. "Grievance Procedures in Nonunion Workplaces: An Empirical Analysis of Usage, Dynamics, and Outcomes." Chicago-Kent Law Review, 66(3): 823-844.

Lewin, David. 1999. "Theoretical and Empirical Research on the Grievance Procedure and Arbitration: A Critical Review." In Employment Dispute Resolution and Worker Rights in the Changing Workplace, edited by Adrienne E. Eaton and Jeffrey H. Keefe, pp. 137-186. Champaign, IL: Industrial Relations Research Association.

Lewin, David, and Richard B. Peterson. 1988. The Modern Grievance Procedure in the United States. Westport, CT: Quorum.

Lewin, David, and Richard B. Peterson. 1990. "The Nonunion Grievance Procedure: A Viable System of Due Process?" Employee Responsibilities and Rights Journal, 3(1): 1-18.

Long, J. Scott. 1997. Regression Models for Categorical and Limited Dependent Variables. Thousand Oaks, CA: Sage.

McCabe, Douglas M. 1997. "Alternative Dispute Resolution and Employee Voice in Nonunion Employment: An Ethical Analysis of Organizational Due Process Procedures and Mechanisms - The Case of the United States." Journal of Business Ethics, 16: 349-356.

Osterman, Paul. 1994. "How Common is Workplace Transformation and How Can We Explain Who Does It?" Industrial and Labor Relations Review, 47(2): 173-188.

Osterman, Paul. 2000. "Work Organization in an Era of Restructuring: Trends in Diffusion and Effects on Employee Welfare." Industrial and Labor Relations Review, 53(2): 179-196.

Slichter, Sumner H., James J. Healy, and E. Robert Livernash. 1960. The Impact of Collective Bargaining on Management. Washington, DC: Brookings Institution.

Stone, Katherine. 1999. "Employment Arbitration under the Federal Arbitration Act." In J. Keefe and A. Eaton, eds., Employment Dispute Resolution in the Changing Workplace. IRRA. 
TABLE 1

Descriptive Statistics

\begin{tabular}{lrrrr}
\hline & Overall & Overall & Nonunion & Union \\
Variable & Mean & S.D. & Mean & Mean \\
\hline Grievance rate (per 100 e'ees) & 3.1 & 4.8 & 2.0 & 5.3 \\
Appeal proportion & .31 & .35 & .18 & .55 \\
Unionization & .34 & .47 & n.a. & n.a. \\
Peer review & .16 & .36 & .24 & n.a. \\
Nonunion arbitration & .17 & .38 & .26 & n.a. \\
Self-managed teams & .26 & .44 & .29 & .20 \\
Electronic monitoring & .39 & .42 & .34 & .49 \\
Internal job mobility & .46 & .36 & .42 & .54 \\
Customer service & .54 & .50 & .64 & .33 \\
Office technicians & .16 & .36 & .17 & .13 \\
Average pay (\$'000's) & 27.9 & 12.6 & 26.7 & 30.5 \\
Unemployment rate & 4.4 & 2.1 & 4.1 & 5.1 \\
Average education $(y r s)$. & 13.2 & 1.4 & 13.5 & 12.7 \\
Low tenure (<1 yr.) & 21.2 & 23.6 & 25.2 & 13.4 \\
\hline
\end{tabular}


TABLE 2

Correlation Matrix.

\begin{tabular}{l|rrrrrrrrrrrrrr} 
& 1 & 2 & 3 & 4 & 5 & 6 & 7 & 8 & 9 & 10 & 11 & 12 & 13 & 14 \\
\hline 1. Grievance rate (log) & 1.00 & & & & & & & & & & & & \\
2. Appeal proportion & 0.73 & 1.00 & & & & & & & & & & \\
3. Union & 0.44 & 0.50 & 1.00 & & & & & & & & & \\
4. Peer review & -0.02 & -0.01 & -0.31 & 1.00 & & & & & & & & \\
5. Nonunion arbitration & 0.05 & 0.04 & -0.33 & 0.29 & 1.00 & & & & & & & \\
6. Self-managed teams & -0.06 & -0.07 & -0.11 & 0.23 & 0.23 & 1.00 & & & & & & & \\
7. Electronic monitoring & 0.17 & 0.17 & 0.17 & -0.02 & -0.09 & 0.04 & 1.00 & & & & & & \\
8. Internal job mobility & 0.05 & 0.22 & 0.15 & -0.04 & -0.01 & 0.03 & -0.02 & 1.00 & & & & & \\
9. Customer service & -0.11 & -0.22 & -0.30 & 0.06 & 0.10 & -0.06 & 0.06 & -0.17 & 1.00 & & & & \\
10. Office technicians & 0.04 & 0.10 & -0.05 & -0.01 & 0.01 & 0.13 & -0.07 & -0.05 & -0.46 & 1.00 & & & \\
11. Average pay (log) & 0.20 & 0.27 & 0.24 & -0.05 & 0.00 & 0.01 & -0.25 & 0.07 & -0.25 & 0.09 & 1.00 & & & \\
12. Local unemployment (\%) & 0.03 & 0.05 & 0.23 & 0.07 & 0.01 & 0.02 & -0.09 & 0.14 & -0.15 & 0.00 & -0.08 & 1.00 & \\
13. Average education (yrs.) & -0.07 & -0.11 & -0.25 & 0.07 & 0.02 & -0.02 & -0.22 & -0.11 & 0.17 & 0.08 & 0.49 & -0.25 & 1.00 \\
14. Tenure (\% <1yr.) & -0.08 & -0.19 & -0.24 & -0.01 & 0.00 & 0.03 & 0.16 & -0.27 & 0.19 & -0.05 & -0.28 & -0.17 & 0.11 & 1.00
\end{tabular}

Correlations with $|\mathrm{r}| \geq 0.15$ are significant at the $\mathrm{p}<.05$ level 
TABLE 3a

\section{ALL ESTABLISHMENTS}

Mean Disciplinary Grievance Rates and Appeal Proportions by Unionization and Presence of Self-Managed Teams

\begin{tabular}{lc|cc}
\hline $\begin{array}{l}\text { Disciplinary grievance rate: } \\
\text { (Annual grievances per 100 employees) }\end{array}$ & & & \\
& Overall & Teams & No Teams \\
Nonunion establishments & 2.0 & 1.7 & 2.1 \\
Unionized establishments & 5.3 & 6.1 & 5.1 \\
& & & \\
Appeal proportion: & & & \\
(Proportion of discipline appealed) & & & \\
& Overall & Teams & No Teams \\
Nonunion establishments & .18 & .20 & .17 \\
Unionized establishments & .55 & .46 & .57 \\
\hline
\end{tabular}

TABLE $3 b$

NONUNION ESTABLISHMENTS

Mean Disciplinary Grievance Rates and Appeal Proportions by Type of Dispute Resolution Procedure and Presence of Self-Managed Teams

\begin{tabular}{lc|cc}
\hline $\begin{array}{l}\text { Disciplinary grievance rate: } \\
\text { (Annual grievances per 100 employees) }\end{array}$ & & & \\
& Overall & Teams & No Teams \\
Peer review & 2.9 & 2.7 & 3.1 \\
Nonunion arbitration & 3.2 & 2.7 & 3.6 \\
Other procedures & 1.3 & 0.4 & 1.5 \\
& & & \\
Appeal proportion: & & & \\
(Proportion of discipline appealed) & & & \\
& Overall & Teams & No Teams \\
Peer review & .30 & .36 & .25 \\
Nonunion arbitration & .34 & .27 & .40 \\
Other procedures & .11 & .09 & .11 \\
\hline
\end{tabular}


TABLE 4

Predictors of Disciplinary Grievance Rates and Appeal Proportions (tobit)

\begin{tabular}{|c|c|c|c|c|}
\hline & \multicolumn{2}{|c|}{ Nonunion Establishments } & \multicolumn{2}{|c|}{ Unionized Establishments } \\
\hline & $\begin{array}{l}\text { Log of Annual } \\
\text { Grievances } \\
\text { ( per } 100 \text { e'ees) } \\
\text { (1) }\end{array}$ & $\begin{array}{l}\text { Appeal } \\
\text { Proportion } \\
\text { (2) }\end{array}$ & $\begin{array}{c}\text { Log of Annual } \\
\text { Grievances } \\
\text { (per } 100 \text { e'ees) } \\
\text { (3) }\end{array}$ & $\begin{array}{c}\text { Appeal } \\
\text { Proportion } \\
\text { (4) }\end{array}$ \\
\hline Peer review & $\begin{array}{l}0.648^{* *} \\
(0.291)\end{array}$ & $\begin{array}{l}0.273^{* *} \\
(0.114)\end{array}$ & & \\
\hline Nonunion arbitration & $\begin{array}{l}0.938 \text { *** } \\
(0.241)\end{array}$ & $\begin{array}{l}0.376^{* * * *} \\
(0.101)\end{array}$ & & \\
\hline Self-managed teams & $\begin{array}{l}-0.677^{* *} \\
(0.308)\end{array}$ & $\begin{array}{l}-0.196 * \\
(0.110)\end{array}$ & $\begin{array}{r}0.173 \\
(0.233)\end{array}$ & $\begin{array}{l}-0.267 \text { *** } \\
(0.100)\end{array}$ \\
\hline Electronic monitor & $\begin{array}{r}0.191 \\
(0.382)\end{array}$ & $\begin{array}{c}0.136 \\
(0.148)\end{array}$ & $\begin{array}{l}0.744 \text { *** } \\
(0.200)\end{array}$ & $\begin{array}{l}0.488^{* * *} \\
(0.094)\end{array}$ \\
\hline Internal job mobility & $\begin{array}{l}0.201 \\
(0.328)\end{array}$ & $\begin{array}{l}0.246 * \\
(0.131)\end{array}$ & $\begin{array}{l}-0.060 \\
(0.312)\end{array}$ & $\begin{array}{l}0.342 \text { ** } \\
(0.163)\end{array}$ \\
\hline Customer service & $\begin{array}{l}0.164 \\
(0.409)\end{array}$ & $\begin{array}{l}0.037 \\
(0.141)\end{array}$ & $\begin{array}{l}0.536^{* *} \\
(0.226)\end{array}$ & $\begin{array}{l}0.225 * \\
(0.135)\end{array}$ \\
\hline Office technicians & $\begin{array}{l}0.659 \\
(0.463)\end{array}$ & $\begin{array}{r}0.254 \\
(0.163)\end{array}$ & $\begin{array}{c}0.092 \\
(0.319)\end{array}$ & $\begin{array}{l}0.389 \text { *** } \\
(0.128)\end{array}$ \\
\hline Average pay & $\begin{array}{l}0.327 \\
(0.444)\end{array}$ & $\begin{array}{l}0.149 \\
(0.158)\end{array}$ & $\begin{array}{l}0.875^{* * *} \\
(0.318)\end{array}$ & $\begin{array}{l}0.878^{* * * *} \\
(0.178)\end{array}$ \\
\hline Unemployment rate & $\begin{array}{r}-0.067 \\
(0.079)\end{array}$ & $\begin{array}{r}-0.021 \\
(0.031)\end{array}$ & $\begin{array}{l}-0.055 \\
(0.034)\end{array}$ & $\begin{array}{l}-0.056 \text { ** } \\
(0.027)\end{array}$ \\
\hline Average education & $\begin{array}{r}-0.032 \\
(0.122)\end{array}$ & $\begin{array}{r}-0.008 \\
(0.047)\end{array}$ & $\begin{array}{l}-0.207 * \\
(0.122)\end{array}$ & $\begin{array}{l}-0.157^{*} \\
(0.081)\end{array}$ \\
\hline Low tenure $(<1 \mathrm{yr}$.) & $\begin{array}{l}0.006 \\
(0.007)\end{array}$ & $\begin{array}{l}0.003 \\
(0.002)\end{array}$ & $\begin{array}{c}0.002 \\
(0.003)\end{array}$ & $\begin{array}{r}-0.003 \\
(0.002)\end{array}$ \\
\hline Constant & $\begin{array}{c}0.333 \\
(1.850)\end{array}$ & $\begin{array}{r}-0.115 \\
(0.746)\end{array}$ & $\begin{array}{l}4.095 * * * \\
(1.507)\end{array}$ & $\begin{array}{l}2.733^{* * * *} \\
(0.962)\end{array}$ \\
\hline Model Chi Sq & $31.59 * * *$ & $24.94^{* * *}$ & $54.08 * * *$ & $69.96 * * *$ \\
\hline $\mathrm{N}$ & 119 & 119 & 61 & 61 \\
\hline
\end{tabular}

$* \mathrm{p}<.10 ; * * \mathrm{p}<.05 ; * * * \mathrm{p}<.01$, standard errors in parentheses. 
TABLE 5

Mean Employee Success Rates by Type of Procedure as a Percentage of Grievances and of Disciplinary Decisions

\begin{tabular}{lcc}
\hline \multicolumn{1}{c}{ Type of Procedure } & $\begin{array}{c}\text { Successful Appeals as a } \\
\text { Percentage of Disciplinary } \\
\text { Grievances }\end{array}$ & $\begin{array}{c}\text { Successful Appeals as a } \\
\text { Percentage of Disciplinary } \\
\text { Decisions }\end{array}$ \\
\hline Union grievance procedures & 36.4 & $17.3^{* * *}$ \\
Nonunion procedures: & 30.0 & $9.9 *$ \\
Peer review & 36.4 & $11.1^{* *}$ \\
Nonunion arbitration & 46.4 & 2.7 \\
Other nonunion procedures & 4
\end{tabular}

$* \mathrm{p}<.10 ; * * \mathrm{p}<.05 ; * * * \mathrm{p}<.01$ : success rates significantly higher than for 'other nonunion procedures' category. 